\title{
Revision of the Genus Prosimulium Roubaud (Diptera, Simuliidae) of Japan I. hirtipes-group in the Subgenus Prosimulium
}

\author{
Kiichi Uemoto, * Osamu ONISHI* and Takeshi ORII* \\ Sanitary Pest Control Section, Epidemic Prevent Center, Kyoto City
}

(Received : December 12, 1972)

\begin{abstract}
In this paper, we presented a revision of Japanese black-flies belonging to the Prosimulium hirtipes-group with the description of a new species and the key to species occurring in Japan.

After making procise examinations of the specimens belonging to the $P$. hirtipesgroup of all stages collected from several localities of Japan, it was ascertained that the all of specimens, which have been regarded as $P$. hirtipes (Fries, 1824) since 1954, were distinctly separable from those of $P$. hirtipes s. str. from Northern Europe. The names $P$. kiotoense Shiraki 1935 and $P$. jezonicum (Matsumura, 1931), which had been adopted for Japanese specimens, were both resurrected basing on significant differences observed between specimens collected from Kyoto and those from Hokkaido.
\end{abstract}

\section{INTRODUCTION}

In Japan, the black-flies belonging to the Genus Prosimulium are found in northern half of the country as far as the lowland is concerned. The southern boundary of the distribution area could approximately be represented by the latitude $35^{\circ} \mathrm{N}$ which passes along nearly the southern coast line of Honshu, the main land of Japan. In the southern half of the country beyond the boundary in question, the breeding place of this genus are limited only at those highlands having an altitude of about $1,000 \mathrm{~m}$ above the sea-level, so that this genus are sporadically located in the Kii Peninsula of Honshu, as well as in Shikoku and Kyushu.

Up to 1940, four species of the present genus were reported from Japan by several authors. These species of the present genus were as follows: (1) Simulium jezonicum Matsumura, 1931, (2) Prosimulium yezoense Shiraki, 1935, (3) Prosimulium kiotoense Shi-

* 上本騏一, 大西 修, 折井 健 : 京都市防疫事務所

(京都市中京区壬生東高田町) raki, 1935, and (4) Helodon sapporoense Shiraki, 1935.

However, since it was pointed out by Kono and Takahasi (1940) that the fourth species is a synonym of the first one, the number of species in question should be reduced to three. Moreover, since Edwards (1931) suggested that Genus Helodon is a synonym of Genus Prosimulium, it would be reasonable to consider that all of the three species would exclusively belong to the Genus Prosimulium.

Since 1941, several authors such as Ogata and Sasa (1954, 1955), 406 Medical General Laboratory (1955), and Shogaki (1956) have described only two species, i.e., P. yezoense Shiraki and $P$. hirtipes (Fries), as the constituents of Genus Prosimulium in Japan. However, none of the authors stated a definite explanation on the reason why $P$. kiotoense and $P$. jezonicum should be considered as the synonyms of $P$. hirtipes.

It has generally been accepted that it is very difficult to distinguish each species of this genus from others, without making comparative examinations of specimens, not only 
of adults insects, but also of pupae and larvae. However, none of the paper mentioned above has made sufficient discussion basing on the differences found in larval characters. Therefore, it is quite probable that the species reported as $P$. hirtipes in the references in question should comprise several different species which are distinguishable by their larval characters only.

From the viewpoint stated above, we have been making efforts in collecting larval, pupal and adult specimens of the insects belonging to the Genus Prosimulium at various localities in Japan since 1964. The object of the study was to revise the classification of the genus with the more precise foundation than before, laying emphasis on the larval characters of each species. At present, it may be given as a conclusion of the reseach that the Genus Prosimulium in Japan consists of at least six valid species distributing among two subgenera.

In this paper, we presented a key and the revised descriptions of each species on the Japanese hirtipes-group of the Subgenus Prosimulium. The yezoense-group of the Subgenus Prosimulium and the Subgenus Distosimulium will be treated in further reports which will be published within a couple of years.

Recently, two different definitions on the subgenera of Genus Prosimulium were proposed; one to Ethiopian and Australian species by Dr. R. W. Crosskey (1969), and the other to the Nearctic species by Dr. B. W. Peterson (1970). In reference to Crosskey's system, some of his subgenera such as Subgenus Paracnephia, Subgenus Procnephia, seems to deviate from the classic definition of Genus Prosimulium (e.g. A. Stone, 1963). Therefore, the definition of Prosimulium (apud Crosskey) may comprehend some species belonging to the other genera, such as Cnephia (Stergopterna), Simulium (Eusimulium) which were not re-defined strictly by him.

The taxonomical arrangement used by Peterson is more familiar to the species of Japan, and his proposed subgenus seems quite suitable for the classification of immature stages of the fly as well as its adult stage. Therefore, Peterson's system along with the terminology was adopted for our present study on the classification of Japanese Prosimulium species.

\section{Genus Prosimulium Roubaud}

Genotype: Simulium hirtipes Fries

(designated by Malloch, 1914)

The characters of each stage of this genus definited by Peterson (1970) may be summarised as follows :

Adults: Antenna with 7-9 flagellomeres; cibarium unarmed. Costa with fine setae only, spinules absent; radius sector with long fork; small basal cell present. Upper anepisternal and lower katepisternal portions separated by a wide, shallow excavation. Calcipala and pedisulcus absent. Endoparameral organ of male simple, generally platelike, without spines.

Pupae: Respiratory organ with 9 to well over 100 filaments. Segment IX of abdomen with a dorsal pair of long terminal spines. Cocoon a loose to densely woven sleeve, lacking definite shape.

Larvae: Basal two segments of antennae pale, distal two segments darkly pigmented. Tips rays of secondary fan, when expanded, falling in a straight line. Median tooth of hypostomium trifid. Rectal gills of three simple lobes.

There is no species that do not fall under these definitions among Japanese Prosimulium, and also undiscernible species (ex. Cnephia abdita Peterson, 1962) has not been found in Japan.

\section{Subgenus Prosimulium}

Genus Prosimulium was devided by Peterson into following four subgenera, Distosimulium, Parahelodon, Helodon and Prosimulium. Up to the present, all species of Prosimulium reported from Japan fall into the Subgenus Prosimulium defined as above, and these can be devided into two speciesgroup, i.e., $P$. hirtipes-group and $P$. yezoensegroup. The distinctive characters of Subgenus Prosimulium from other subgenera, provided by Peterson, may be summarised as follows :

Female: Ovipositor lobe long, reaching or extending beyond anal lobe. Spermatheca 
always with a large differentiated circular area at junction with spermathecal duct. Claw simple or, at most, with a small inconspicuous subbasal tooth.

Male: Ventral plate with a prominent, ventrally directed lip, or emargination. Median sclerites $\mathrm{Y}$-shaped at base, at most, projecting proximally from its point attachment only a short distance between basal arms of ventral plate.

Larva. Lateral plate of proleg broad, with a well-developed vertical portion.

\section{Prosimulium hirtipes Group}

$P$. hirtipes group adopted in this paper is not equivalent to Rubzov's hirtipes-group (1960), but to P. mixtum group of Peterson, with the exception of the inhabitants in Palaearctic region. The characters of $P$. mixtum group defined by Peterson may summarised as follows :

Female: Spermatheca normal in size, generally longer than broad; cercus and anal lobe shorter, setting at nearly a right-angle to tip of abdomen.

Male: Distimere generally narrower, with 2-3 apical spines.

Pupa: Respiratory organ with $12-16$ filaments.

Larva: Abdominal segments V-VIII enlarged abruptly.

Male characters of this group are not well-defined from those of other group in the Subgenus Prosimulium, as cited above. Therefore, it is necessary to examine the male insect together with the pupa from which it emerged.

This group includes the following species from the Continents.

Europa : P. (P.) hirtipes (Fries); $P . \quad(P$. luganicum Rubzov; $P$. (P.) inflatum Davies; $P$. (P.) fuscipes (Roser); $P$. (P.) rufipes (Meigen); $P$. (P.) conistylum Rubzov

Sibilia: $P .(P$.$) diminutum Rubzov; P .(P$. tridentatum Rubzov; $P$. $(P$.) irritans Rubzov

\section{Key to THE JAPANESE SPECIES IN $P$. hirtipes GROUP}

\section{Female}

1. Wing with narrow, indistinct basal cell. .P. kiotoense

Wing with broad, distinct basal cell....2.

2. Ovipositor lobes, with concave, lateral margin, and medial margins of them divergent distally from each other.

P. jezonicum

Ovipositor lobes, with convex, lateral margin, and medial margins of them subparallel. P. kanii n. sp.

\section{Male}

1. Hind basitarsus less than 2.5 time as long as 2 nd tarsal segment.........P. kiotoense Hind basitarsus about 3 times as long as 2 nd tarsal segment.........................2.

2. Basimere of genitalia broad, about $4 / 5$ as wide as long. Posterior margin of ventral plate strongly concave in ventral view.............................. jezonicum Basimere of genitalia slender, about $2 / 3$ as wide as long. Posterior margin of ventral plate nearly straight.

P. kanii $\mathrm{n}$. $\mathrm{sp}$.

\section{Pupa}

1. Dorsal trunk of respiratory organ not divergent from ventral trunks........P. kiotoense Dorsal trunk of respiratory organ strongly divergent from ventral trunks.............2.

2. Four pairs of filaments rising from ventral trunks, respectively, with a short petiole............................. jezonicum One of four pairs of filaments rising from ventral trunks sessile......... kanii $\mathrm{n}$. sp.

\section{Larva}

1. Inner subapical margin of mandible with 4-6 rugged serrations. $P$. kiotoense Inner subapical margin of mandible with more than 8 fine serrations...............2.

2. Median tooth of hypostomium higher than the highest lateral tooth.....P. jezonicum Median tooth of hypostomium as high or lower than the highest lateral tooth.

P. kanii n. sp. 


\section{Prosimulium (Prosimulium) kiotoense Shiraki}

Prosimulium kiotoense Shiraki, 1935, Memo. Fac. Agr. Taihoku Imp. Univ., 16 (1) : 6, Pl, VI, fig. 1-9.

Prosimulium hirtipes (Fries, 1824); Ogata \& Sasa, 1954, Jap. J. Exp. Med., 24:331; Ogata \& Sasa, 1955, Jap. J. sanit. Zool., 6 (1) : $10 ; 406$ Med. Gen. Lab., The black flies of Jap. \& Kor., $1955: 5$, 5 figs. (1-A, 7-A, 11-A, 20-A, 27-A) ; Shogaki, 1956, Jap. Zool. Magz., 65 (7) : 276, Tb. 2 ; Okamoto, 1958, J. Yonago Med. Asos., 9 (4) : 581.

Prosimulium kiotoense was described by Shiraki (1935) basing on two females collected from Kyoto, and is mainly distributed in south-western areas of Japan. Kani (1944) first reported its habitats in the basin of Kamo-river near Kyoto. In his paper, this species was called under the Japanese name "Mukashi-buyu No. 1" which can be identified as $P$. kiotoense from the illustration of its pupal respiratory organ. Ogata \& Sasa (1954, 1955), 406 Med. Gen. Lab. (1955), Shogaki (1956) and Okamoto (1958) set up a group of all Prosimuliid-flies which have 16 pupal respiratory filaments and considered that it corresponds to Prosimulium hirtipes (Fries, 1824). However, these authors scarcely made close examinations of the larval stage of the group. On the other hand, we reached a different conclusion from that of previous authors, after making precise examinations of the specimens in various stages collected from several localities involving the type area of $P$. kiotoense. Here, a revised description of this species will be given as follows :

\section{Discription}

Female. General body color greyish black to black. Length : body, 3.5-4.4 mm ; Wing, 3.1-4.2 mm.

Head black, faintly greyish pollinose. Frons broad, at vertex about twice as wide as at narrowest point, from $1 / 3$ to $1 / 2$ as wide as head and about as long as wide; sparsely covered with long, decumbent, yellow pile mixed with a few black hairs. Clypeus slightly longer than broad, usually paler than frons, rather densely covered with whitish yellow pollinose on dorsal margin than on lateral margin, rest of surface sparsely covered over with ventrally directed, long greyish black pile. Occiput rather densely covered with moderately long, yellow pile than frons; postocular setae long, black, usually bending over hind margin of eye. Antenna with 11-segments, blackish brown; both distal margins of scape and pedicel light yellow; first flagellomere slightly longer than pedicel; distal half portion of first segment and rest of flagellum with fine golden pubescence; both distal margins of scape and pedicel with fringe of pale hairs. Mandible with about $42-50$ serrations. Blade of maxilla with 26-29 retrorse teeth. Palpus browinish black, with black hairs admixed with some yellow hairs; segment $\mathrm{V}$ about $1 / 4$ longer than segment III. Sensory vesicle moderately long, slightly less than $1 / 2$ as long as its segment, proximally situated; neck arising from anterior margin, extending anterodorsally and expanding distally into round mouth. Median distal space of cibalium broad, shallow, a squared U-shape; dorsolateral arms rather long, slender, heavily sclerotized.

Thorax brownish-black to black, faintly yellowish-white pollinose. Pronotum often lighter yellow than scutum, with moderately long, semi-erect, yellow pile. Scutum uniformly black, rather sparsely clothed with short, recumbent, golden yellow pile than pronotum; pile somewhat longer and more erect posteromedially. Scutellum concolorous with scutum, covered with long, erect, golden pile laterally. Postscultellum concolorous with scutum, faintly shining. Pleuron concolorous or slightly darker than scutum, faintly whitish grey pollinose ; pleural membrane dark reddish-brown to black; mesepimeral tuft yellow. Wing membrane hyaline; veins yellowish brown; hairs on stem vein dark brown, those on base of costa with mixed coloration of yellow and dark, rest of hairs dark; fringe of calypter and alar lobe golden yellow. Halter browish yellow basally, more brown apically; stem with short, yellow pile. Legs brownish yellow to dark brown; all coxae, distal half of all trochanters, extermely apical tips of all femora, both end of all tibiae and all tarsi 
darkened; covered with yellow pile and intersparsed with a few dark hairs, pile on posterior surface of femora longer than other segments, especially on front femora; hairs of tarsi dark, mixed with some yellow ones; hind basitarsus 5.0-5.5 times as long as broad. Claw gently curving, usually simple or sometimes with extremely minute subbasal tooth.

Abdomen orange-brown to blackish-brown, mottled, segments VI-IX often dark brown; tergites II-V reduced, III smallest; rather sparsely covered with moderately long, pale yellow pile and with some dark hairs on last three or four segments; pleural regions more densely covered with moderately long to long, pale yellow pile; sternite VII moderately sclerotized, shield-shaped. Basal fringe of long, pale yellow pile. Genitalia as shown in Fig. 1. Anal lobe broadly L-shaped, projecting posteroventrally beneath cercus but not extending beyond its hind margin. Cercus subquadrate, about twice as wide as long, hind margin rounded. Ovipositor lobes moderately long, reaching to about middle of anal lobes, rather slender; outer margins slightly concave distally, inner margins slightly concave basally, narrowly sclerotized, parallel and approaching to each other distally, tips rounded; moderately setose. Stem of genital fork long, slender, heavily sclerotized; arms relatively short, curved, tapering distally, expanding into large subquadrate plates that are more densely sclerotized along medial margins, posteromedial corner produced into moderately long, pointed, processes; narrowly attached to segment IX. Spermatheca relatively short, hemispherical, broadly rounded distally, moderately pigmented, with a reticulate pattern.

Male. General body color dark brown to greyish-black. Length: body, $3.4-4.1 \mathrm{~mm}$; wing, $3.2-3.8 \mathrm{~mm}$.

Frons and clypeus with erect brown pile. Occiput with mixed, long, pale yellow and brown hairs, yellow hairs more dense laterally, dark hairs more dense dorsally. Antenna dark brown to black with light brown pubescence; segment III larger than pedicel. Palpus dark brown with pale brown pile; sensory vesicle small, about $1 / 4$ as long as its segment; neck rather long, enlarging to form an ovate mouth.

Pronotum concolorous or slighly lighter than scutum; with pale yellow pile. Scutum brownish black to black, rather sparsely covered with short, recumbent, pale yellow pile than female; pile longer and more erect posteromedially. Scutellum dark brown with long yellow hairs. Postscutellum greyish black, subshining. Pleuron concolorous or slightly lighter than scutum, with faintly yellowish grey pollinose; pleural membrane brown; mesepimeral tuft pale yellow. Wing membrane hyaline; vein greyish brown; hairs on stem vein varying from dark brown to mixed coloration of dark brown and pale yellow, or to all pale yellow; fringe of calypter and alar lobe pale yellow. Halter brownish yellow with pale yellow pile. Coxae and trochanters dark brown, with brown pile; femora and tibiae yellowish brown, apices of femora and both ends of tibiae darkened; with mixed long pale yellow hairs and short brown hairs; both ends of basitarsi and rest tarsal segments brownish black, with brownish black hairs; hind basitarsus swollen, but not spindleshaped, both side of its segment subparallel, about 3.5-3.7 times as long as width, about $2.3-2.5$ times as long as 2 nd tarsal segment.

Abdomen brownish black; tergites subshining except for hind margins which are dull greyish brown pollinose; tergites covered with yellowish brown to brown pile; tergite $\mathrm{X}$ small subquadrate, as long as width; sternites with long, light yellowish brown pile. Pile of basal fringe long, pale yellow. Genitalia as shown in Fig. 4. Basimere about $3 / 5$ as broad as length. Distimere about $3 / 4$ as long as basimere and about $2 / 3$ as wide as length, only slightly curved, obliquely pointed, with 3-4 terminal spines. Ventral plate broad, slightly concave dorsally; in ventral view, tapering distally, apex rather rounded with a short, rather broad, ventral lip; stem of median sclerite usually shorter than arms, moderately sclerotized; its arms slightly sclerotized; in posterior view, slender, spindle-shaped, pointed at ends. Plate of endoparameral organ slightly broader than high, inner margin indefinite, slightly wrinkled; lightly to moderately sclerotized.

Pupa. Length 5.2-6.4 mm. Respiratory 
organ (Fig. 15) 2.7-3.9 mm, often longer than $1 / 2$ length of pupa ; consisting of 16 filaments in a loose clump that is longer than width in lateral view; base short, moderately broad and covered with minute spicules ; base giving rise to 3 short trunks; dorsal trunk usually longest and branching into 3 secondary trunks, a lateral trunk with 3 filaments, a medial trunk with 3 filaments and between them 2 longer trunk with 2 filaments, ventral trunk branching subsequent into 2 petiolate pairs of filaments, a outer pair with longer petiole than a inner pair; lateral trunk with 2 petiolate pairs of filaments, a outer pair usually with longer petiole than a inner pair; filaments greyishbrown, slender and slightly tapering, with numerous, moderately deep, transvers furrows. Head with slightly raised granules; antenna of female reaching hind margin of head; antenna of male extending about onehalf distance to hind margin of head. Dorsum of thorax with a distinct but superficial reticulate pattern and with numerous flatened granules; trichoma rather long, slender and sinuous, 3-4 dorsal and 1-3 lateral trichomes on each half of thorax. Tergites I-II each with 6-8 moderately long setae; tergites III-V each with 8 large anteriorly directed hooks along posterior margin; tergites V-IX each with a row of short, fine, posteriorly directed spines near anterior margin ; tergite VIII with 4-6 moderately long setae; each side of tergite IX near middle with a long, stout setae; pleural membrane of segments VIII-IX with moderately long setae. Caudal spines long, bases situated upon rather prominent convexities, tips curving anteriorly and diverging mutually, each with a long, rather sclerotized seta near base anteriorly and posteriorly. Sternite III with several small setae; sternite IV with 4 small spines and several small setae; sternites V-VII each with 4 larger hooks, a lateral hook of VIVII segments lying in pleural membrane. Cocoon varying from thin to thick, loosely woven sleeve, often with incorporated bits of benthos, covering most of pupa, or often to one-half length of respiratory organ.

Larva. Length 7.0-8.5 mm. Body pale greyish-brown to dark yellowish-brown. Head capsule light reddish-brown to medium brown; cephalic apotome usually lighter yellowish or reddish brown anteromedially; head spots dark brown, usually distinct, but rather indistinct posteriorly on some specimens with darker head capsules; eye spots rather small, surrounding clear area usually distinct differentiated from rest of general plate. Antenna distinctly longer than stalk of cephalic fan, proportional length of segments I-IV about $7: 10: 8: 1$. Cephalic fan with $32-38$ rays. Hypostomial teeth as shown in Fig. 23 ; median tooth slightly inclined, distinctly higher than highest lateral teeth; lateral tines of median tooth about as high as highest sublateral teeth; sublateral tooth III highest of all sublateral teeth, slightly lower than outer lateral tooth VII; inner and outer sublateral teeth III, V conspicuously flanged. Postgenal cleft shallow, apex almostly truncat, slightly widening posteriorly. Postgenal bridge slightly longer than hypostomium. Inner subapical margin of mandible with 4-6 rigged serrations. Maxillary palpus2.7-3.2 times as long as width at base. Lateral plate of proleg moderately sclerotized, extending more than one-half length of apical segment. Rectal setulae present. Anterodorsal arms of anal sclerite slightly longer than posteroventral arms. Posterior circulet consisting of $12-18$ hooks in about $84-92$ rows.

Holotype. Female, Entomological Museum of the Government Research Institute, Taikoku, Taiwh.

Type Lacality. Kyoto, Japan, April 19, 1914, Shiraki.

Record (Map 1). Material examined. Honshu : Myoko-piemont (Niigata Pref.)-Sekistream, 27-IV-1966, K. Uemoto; Kyoto Prefecture, 19-IV-1914, A. Nohira, (female only); Kyoto city-Momoi-stream, 15-IV-1965, T. Orii ;-Takano-stream, 10-III-1965, T. Orii ;-Kusao-stream, 30-IV-1968, A. Yamaguchi ;-Kikko-stream, 17-III-1964, T. Orii ; -Takano basin, 25-IV-1971, N. Kumasawa (female only); Nagato city (Yamaguchi Pref.), 4-III-1970, Y. Tabaru; Taga town (Shiga Pref.)-Seri-stream, 10-III-1969, K. Uemoto; Sama town (Tottori Pref.)-Amidastream, 8-V-1965, K. Uemoto (pupa only).

Other Record. Tottori Pref. (Okamoto, 1958); Niigata Pref. (A. Watabe et al., 
1956).

Remarks. It is not easy to differentiate adults of Japanese $P$. hirtipes-group from those of $P$. hirtipes (Fries) by the form of the female or male genitalia. However, larvae of these species are readily distinguishable from those of $P$. hirtipes in the form of postgenal cleft, in the height of hypostomial median tooth or usually in the roughness of mandibular inner serrations.

Larvae of $P$. kiotoense are closely similar to those of $P$. hirtipes in the arrangement of mandibular inner serrations, but are differentiated from those of $P$. hirtipes in the height of hypostomial median tooth, and in the form of postgenal cleft. Pupae of this species and $P$. hirtipes are very similar to each other and can be distinguished only by the rising form of respiratory filaments; i.e. in $P$. kiotoense, one of 2 pairs of filaments rising from ventromedial or ventrolateral trunk has a much longer petiole than the other pair, while in $P$. hirtipes, the petiole of the one pair from the trunk is nearly as long as that of the other pair. Although adults of this species have resemblances to those of $P$. hirtipes, they are differentiated from the latter, at least, in the following features: wings of the female with more narrowing basal cell, or hind basitarsi with subparallel both sides, and longer, slender hind 2 nd tarsi of the male.

Larvae, pupae and adults of $P$. kiotoense and those of other species in $P$. hirtipesgroup from Japan are easily separable by the features given in the key.

Biological Notes. P. kiotoense is a univoltine species that overwinters in the larval stage, but its life history and behaviours are little known. Young larvae first appear about mid November, grow during winter and pupate in March in Kyoto-Prefecture. Larvae and pupae inhabit on submerged vegetations or debris in rapid, upland streams being about 2 to $5 \mathrm{~m}$. in width, i.e. in the transiting type from the spring type to the ravine type of the river divisions defined by Kani (1952) and Orii et al. (1964). Its attacking behaviours on man and animals were well known, but it seems to prefer the latter to the former in Kyoto.

\section{Prosimulium (Prosimulium) jezonicum (Matsumura)}

Simulium crassitarsis Macquart, 1834; Matsumura, 1915, Konchu Bunruigaku II : 50 ; Matsumura, 1915, Dainippon Gaichu Zensho II : 786, Pl. XXXXV, fig. 6.

Simulium jezonicum Matsumura, 1931, Ins. Jap. Emp. III : 406, fig. 295.

Helodon sapporoensis Shiraki, 1935, Memo. Fac. Sci. Agr. Taihoku Imp. Univ., 16 (1) : 10, Pl. VII, figs. 1-7.

Helodon jezonicum (Matsumura, 1931) ; Kono \& Takahasi, 1940, Ins. Matsmurana, XIV $(2,3)$ : 80.

Prosimulium hirtipes (Fries, 1824); Ogata \& Sasa, 1954, Jap. J. Exp. Med., $24: 331$; Ogata, L 955, Jap. J. Appl. Zool., 20 (1, 2) : 84, Tb. I. ; 406 Med. Gen. Lab., 1955, The black flies of Jap. \& Kor. : 5 .

Matsumura (1915) first gave a brief report on this species which had been known as a serious pest in Hokkaido with the name as Simulium crassitarsis Macquart, 1834. Then, he described this species as a new species, Simulium jezonicum, in 1931. Also, Shiraki (1935) described 16 females of Prosimuliid flies biting man in Sapporo, Hokkaido as Helodon sapporoensis n. sp., without making a through investigation on the type specimens of $S$. jezonicum Matsumura. In 1940, Kono and Takahasi regarded $H$. sapporoensis Shiraki as a synonym of Simulium jezonicum Matsumura after examining the descriptions and specimens, and transfered the latter into the Genus Helodon Enderlein, 1921.

Since Ogata \& Sasa (1954) and 406 Med. Gen. Lab. (1955) commented one after another on the fauna of the black fly of Japan, this species has been lumped together with Prosimulium kiotoense Shiraki and treated as synonyms of $P$. hirtipes (Fries, 1824). However, we believe that this species belongs to $P$. hirtipes-group in the Subgenus Prosimulium Peterson and should be independent from $P$. hirtipes or $P$. kiotoense, because of having the features as follow:

\section{Description}

Female. General body color greyish black to black. Length : body $3.4-4.5 \mathrm{~mm}$; Wing $3.1-4.3 \mathrm{~mm}$. 
Head black, faintly greyish yellow pollinose. Frons black, rather narrow than that of the foregoing species, at vertex less than twice as wide as at narrowest point, about $1 / 3$ as wide as head and slightly longer than width, rather densely covered with moderately long, decumbent, golden yellow pile. Clypeus slightly longer than width, concolorous with frons, densely covered with whitish yellow pollinose at dorsolateral margin; rest of surface sparsely covered over with ventrally directed, long, yellow pile. Occiput concolorous with frons, densely covered with whitish yellow pollinose, and with sparse, short, pale yellow pile ; postocular setae long and stout. Antenna 11segmented, black, excepting with distal margin of pedicel often brownish yellow; scape with distal fringe of longer brownish black hairs; distal margin of pedicel with brownish black pile and pale yellow pollinose; first flagellomere slightly longer than pedicel; distal half portion of first flagellomere and rest of flagellum with fine golden pubescence. Mandible with about 50-55 serrations. Blade of maxilla with 28-32 retrorse teeth. Palpus brownish black, with black hairs admixed with some yellow hairs; segment $\mathrm{V}$ about $1 / 4$ longer than segment III. Sensory vesicle moderately large, from $1 / 3$ to less than $1 / 2$ as long as its segment, proximally, dorsally situated; neck arising from anterior margin, extending anterodorsally and expanding distally into an oval mouth. Median distal space of cibarium moderately deep, rather broad, heavily sclerotized.

Thorax greyish black to black. Pronotum faintly lighter than scutum, whitish grey pollinose, sometimes humerus reddish-brown on anterolateral angle; with long, semi-erect yellow pile. Scutum uniformly black, faintly yellowish grey pollinos; rather densely covered with moderately long, recumbent, golden yellow pile that is longer and more erect laterally and posteromedially. Scutellum concolorous with scutum, covered with long, erect yellow hairs having dark bases, more dense laterally. Postscutellum concolorous with scutum, subshining. Pleuron concolorous with scutum, faintly whitish grey pollinose; pleural membrane varying from dark reddish brown to brownish black; me- sepimeral tuft pale yellow. Wing membrane hyaline; veins light yellowish brown; pile on stem vein dark brown to black; base of costa with mixed yellow and some black hairs, rest of dorsal hairs black; fringe of calypter and alar lobe orange yellow. Halter yellowish brown to dark brown, with pale pile. Coxae and trochanters brownish black to black, with yellow hairs; femora and tibiae varying from greyish-black or brownish black to black, distal tips of femora and both ends of tibiae black; tarsi all black; segments excepting for tarsi densely covered with long, recumbent, golden yellow hairs, tarsi with some short, yellow hairs but dark hairs predominant; hind basitarsus about six times as long as width. Claw evenly curved, usually with a minute subbasal tooth.

Abdomen uniformly brownish-black to black, hind margins of tergites with narrow, brownish grey pollinose; tergites III-V somewhat reduced; sparsely covered with short, golden yellow hairs. Pleural region more densely covered with moderately long yellow pile. Sternite VII heavily sclerotized, shieldshaped; sternite VI variable sclerotized. Basal fringe of long, pale yellow pile. Genitalia as shown in Fig. 2. Anal lobe broader in ventral portion than dorsal, anteroventral margin slightly produced " heel "-like, posteroventral margin conspicuously projecting beneath cercus, extending slightly hind beyond hind margin of cercus, broadly rounded ventrally; moderately setose. Cercus subrectangular, about twice as broad as length, hind margin nearly straight or slightly convex. Ovipositor lobes long, reaching at least to middle of anal lobes; medial margins narrowly sclerotized along more than half of their lengths, slightly concave basally, widely divergent from each distally; lateral margins concave distally; narrowly rounded apically ; moderately setose. Stem of genital fork long, slender, heavily sclerotized; moderately long, widely divergent, expanding distally into large, subtriangular plates, their inner distal margins rather slender, usually produced into moderately long, pointed processes; narrowly attached to segment IX. Spermatheca short, rounded to ovate, moderately pigmented, with a reticulate pattern.

Male. General body color greyish-black to 
black. Length: body $3: 2-4: 4 \mathrm{~mm}$.; wing 3.0-4.1 $\mathrm{mm}$.

Frons and clyprus with erect dark brown to black pile. Occiput dorsally with long, brownish grey hairs and laterally with long, pale yellow pile. Antenna black with golden yellow pubescence; first flagellomere slightly longer than pedicel. Palpus greyish brown with brownish black hairs; sensory vesicle varying from $1 / 4$ to $1 / 3$ as long as its segment; neck short, indistinct, terminating in a slightly enlarged, ovate mouth.

Pronotum black, often lateral corners of humerus reddish brown; with pale yellow pile. Scutum black, lightly yellowish grey pollinose, rather densely covered with short, recumbent, pale yellow pile that is longer laterally and posteromedially. Sctellum black with long, pale yellow hairs. Postscutellum brownish black, subshining. Pleuron black, anteriorly rather densely pale grey pollinose; pleural membrane brownish black; mesepimeral tuft yellow to yellowish brown. Wing membrane hyaline; veins yellowish brown to dark greyish brown; pile on stem and base of costa with mixed yellowish brown and brownish black hairs; fringe of calypter and alar lobe pale yellow. Halter dark brown, with yellowish brown to brown pile. Coxae and trochanter brownish black to black with brownish black pile; remaining segments dark brownish black to black; with brownish black pile and some yellow pile on femora and tibiae; hind basitarsus swollen, but not spindle-shaped; both sides of its segment subparallel, about 3.4-3.6 times as long as width, about 2.8-3.0 times as long as $2 \mathrm{nd}$ tarsal segment.

Abdomen black, with moderately dense black pile, hind margins of tergites narrowly with greyish brown pollinose; basal fringe blackish brown, tips of hairs often grey; tergite $\mathrm{X}$ small, about as long as its width ; sternites with moderately long, brown pile. Genitalia as shown in Fig. 5. Basimere about $4 / 5$ as broad as long. Distimere about $3 / 5$ as long as the length of basimere, about $2 / 3$ as wide at base as length; slightly curving and tapering distally to an obliquely pointed apex with 2 terminal spines. Ventral plate broad, concave dorsally; tapering distally, apex slightly concave, with rather long, considerably broad, pointed ventral lip in ventral view; stem of sclerite moderately broad, slightly longer than arms, moderately sclerotized; its arms slightly sclerotized; in postal view, slightly tapering distally, obliquely pointed at ends. Plate of endparameral organ broader than height, rounded laterally, inner margin slightly wrinkled, lightly to moderately sclerotized.

Pupa. Length 5.4-6.5 mm. Respiratory organ Fig. 16; $2.3-3.4 \mathrm{~mm}$ often about $1 / 2$ length of pupa; consisting 16 filaments in a loose clump, as long as width in lateral view; base short, moderately broad and covered with minute spicules; base giving rise to 3 short, primary trunks; dorsal trunk usually longest and branching into 3 secondary trunks, a medial, a lateral trunk with 3 filaments respectively, and between them a longer trunk with 2 filaments; ventral and lateral trunk giving rise to 2 petiolate pairs of filaments respectively, and usually widely divergent from dorsal trunk; one pair of ventral trunk with far longer petiole than that of the other pair, and petiole of one pair of lateral trunk subequal in length to that of the other, filaments greyish brown, slender and slightly tapering with numerous, moderately deep, transverse furrows. Head with numerous flattend granules; antenna of female reaching hind margin of head; antenna of male extending about $1 / 2$ distance to hind margin of head. Dorsum of thorax with a faint, superficial reticulate pattern and with numerous flattend granules; 3 long, slender, pale dorsal trichomes and 2 lateral trichomes on each lateral half of thorax. Tergites V-IX each with a row of short, fine, posterioriy directed spines near anterior margin, these present on tergite IV but weakly developed; tergites III-IV each with 8 larger, anteriorly directed spines along posterior margin, these present near middle on tergites I-II each, with 4 and 8 but weakly developed; tergite VIII with 4-6 moderately long setae; each side of tergite IX with a moderately lons, stout seta; several similar setae usually present in pleural membrane of segment VIII. Caudal spines long, bases situated upon rather prominent convexities, tips curving anteriorly and diverging, each with a long, rather stout seta near base anteriorly and 
posteriorly. Sternite III usually without hook; sternite IV with 2 small hooks; sternites V-VII each with 4 larger hooks, without lateral hook in pleural membrane. Cocoon varying from a thin to thick sleeve, often with incorporated bits of debris and benthos, usually covering most of pupa.

Larva. Length $8.4-9.5 \mathrm{~mm}$. Body pale greyish brown anteriolry, becoming more brownish-black posteriorly. Head capsule median yellowish brown to dark brown; cephalic apotome lighter brown anteromedially; head spots dark, distinct, median spots darker than other spots; eye spots rather large, surrounding clear area usually distinctly differentiated from rest of general plate. Antenna about as long as stalk of cephalic fan, proportional length of segments I-IV about $6: 10: 6: 1$. Cephalic fan with 26-34 rays. Hypostomial teeth as shown in Fig. 24 median tooth slightly inclined, distinctly highter than highest lateral teeth; lateral tines as high as or slightly higher than highest sublateral teeth; outer lateral tooth VII prominent in height from sublateral teeth; sublateral tooth III slightly higher than sublateral tooth V; tooth III and $V$ strongly flanged. Postgenal cleft shallow, about 3 times as wide as depth, faintly biarctate, widening posteriorly. Postgenal bridge distinctly longer than hypostomium. Inner subapical margin of mandible with 10-13 fine serrations. Maxillary palpus 2.8-3.1 times as long as width at base. Lateral plate of proleg moderately sclerotized, extending three-fourth length of apical segment. Rectal setulae present. Anterodorsal arms of sclerite as long as or slightly shorter than posterovental arms. Posterior circulet consisting of $12-20$ hooks in about 92-98 rows.

Syntype. Female, Entomological Institute, Faculty of Agriculture, Hokkaido University.

Type Locality. Maruyama, Sapporo, Hokkaido, May 23, 1916, Matsumura.

Record (Map 1). Material examined. Hokkaido: Kawayu town, 15-V-1971, K. Uemoto ; Daisetsu-Aizankei - Antaromastream, 17-V-1971, K. Uemoto ; Lake Shikari betsu-Yanbetsu-stream, 14-V-1971 K. Uemoto; Atsuta town, 20-IV-1971, K. Hattori (adults reared only); Sapporo sity-Hoshioki- stream, 24-XII-1971, T. Okazawa (larva only). Honshu: Shichinohe town (Aomori Pref.), 13-VI-1954, K. Ogata (female only);Kuraoka-stream, 24-IV-1970, K. Uemoto (pupa and larva) ; Takahagi town-Hananukistream, 27-II-1972, K. Uemoto (larva only).

Other Record. Hokkaido: Mt. Tokachidake, 1-VI-1939, T. Sawamoto; Mt. Tengudake, 16-VI-1935, S. Sasaki; Mt. Teine, 30-V-1936, S. Sasaki ; Jozankei, 17-V1910, S. Matsumura ; Sappro city, VII-1943, H. Takahasi ;-9-V-1917, S. Matsumura ;15-V-1917, S. Matsumura ;-30-V-1939, H. Aoki ;-May, T. Shiraki. Honshu; Nikko city (Tochigi Pref.), March, T. Shiraki. (According to all of these records, female only)

Remarks. Adults of this large, northern species are readily distinguishable from those of $P$. hirtipes (Fries, 1824) by their forms of female and male genitalia, i.e. $P$. jezonicum (Matsumura) has ovipositor lobes with the distal half of the medial margins being far from each other, and male genitalia with the broader basimeres. Pupae and larvae of this species are differentiated from those of $P$. hirtipes by the widely divergent respiratory organ and the height of the hypostomial median tooth. Adults of this species are also discernible from those of $P$. kiotoense Shiraki by the color of the abdomens, and by the femora and tibiae of hind legs densely covered with long, golden hairs, besides the features given in the key.

Biological Notes. P. jezonicum is a univoltine species and one of most important pests of man or other vertebrates. Their larvae are found on submerged vegetations or debris in rapid streams at foothills during winter season. The adults usually emarge from mid April to early June.

\section{Prosimulium (Prosimulium) kanii new species}

\section{Description}

Female. General body color brownish-black to black. Length: body $3.3-4.3 \mathrm{~mm}$; wing $3.3-3.8 \mathrm{~mm}$.

Head black, faintly greyish pollinose. Frons slightly narrower, at vertex less than twice as wide as at narrowest width, about $1 / 3$ as wide as head and about as wide as 
length sparsely covered with moderately long, decumbent, pale yellow pile. Clypeus slightly longer than width, faintly covered with whitish grey pollinose dorsolaterally, rest of surface sparsely covered with ventrally directed, greyish yellow pile. Occiput densely covered with long, pale yellow pile; postocular setae long, stout, bending over hind margin of eye. Antenna 11-segmented; brownish black, distal 2-3 segments of flagellomere slightly lighter than rest of segments; fine pubescence pale yellow, stouter hairs black; pedicel largest segment. Mandible with $38-42$ serrations. Blade of maxilla with 24-26 retrorse teeth. Palpus brownish black; third segment darker than others, with dark pile; segment $\mathrm{V}$ slightly longer than segment III, distal end of segment III slightly dark brown. Sensory vesicle moderately large, from $1 / 3$ to less than $1 / 2$ as long as its segment, proximally situated; neck arising nearly from anterodorsal margin, and directed vertically, expanding distally into oval mouth. Median distal space of cibarium moderately deep, broadly Ushaped; dorsolateral arms short, moderately broad, heavily sclerotized.

Thorax brownish-black to black. Pronotum black, except anterolateral angles of humerus which are yellowish- to reddish-brown; with moderately long, semi-erect pale yellow pile. Scutum uniformly black, densely covered with short, decumbent, pale yellow pile that is slightly longer posteriorly. Scutellum slightly light brownish, densely covered with long, erect, golden yellow hairs some of which have dark bases. Postscutellum black, surrounded by faintly greyish pollinose, central surface subshining. Pleuron brownish-black to black anteriorly, densely greyish pollinose, becoming darker brown medially and posteriorly, often mottled; pleural membrane light reddish brown; mesepimeral tuft pale yellow. Wing membrane hyaline; light brownish grey; pile on stem vein pale yellow, often mixed with some dark hairs; base of costa with mixed yellow and black hairs; rest of hairs black; fringe of calypter and alar lobes pale yellow. Halter dark yellowish brown to reddish brown, with pale yellow pile. Coxae and trochanters dark blackish-brown; femora and tibiae dark yel- lowish brown, hind tibia darker at both ends; tarsi dark brownish black; segments with some long yellow hairs excepting for tarsi which are covered with slightly shorter, dark hairs interspersed with some yellow hairs; hind basitarsus about 4.7-5.2 times as long as width. Claw simple, or with a minute subbasal tooth, gently curved.

Abdomen brownish-black to black, hind margins of tergites narrowly greyish brown pollinose; tergite IV slightly reduced; tergites moderately covered with pale yellow to dark yellow pile; pleural regions rather densely covered with moderately long pale yellow pile; sternite VII moderately sclerotized, shield-shaped. Basal fringe of long, pale yellow pile. Genitalia as shown in Fig. 3. Anal lobe rather slenderly L-shaped, projecting posteroventrally beneath cercus but not extending beyond its hind margin. Cercus subquadrate, about 2.5 times as broad as length. Ovipositor lobes moderately long, reaching about middle of anal lobes, rather broad; outer margins convex distally; inner margins rather broadly sclerotized, concave basally, subparallel distally, tips slightly pointed; moderately setose. Stem of genital fork long, slender, heavily sclerotized; arms relatively short, slightly curved, tapering distally, expanding into large subquadrate plate having moderately long, pointed processes at anterolateral and posteromedial corners. Spermatheca short, rounded to ovate, moderately pigmented, with a reticulate pattern.

Male. General body color dark brownishblack to black. Length : body, $3.2-3.8 \mathrm{~mm}$; wing, $2.9-3.6 \mathrm{~mm}$.

Frons and clypeus with erect brownishblack pile. Occiput dorsally with long, brownish-black pile and laterally with longer, yellowish-brown pile. Antenna brownish black to black with golden pubescence; first flagellomere longer than pedicel. Palpus black, with brownish black pile; sensory vesicle about $1 / 4$ times as long as its segment length; neck rather long, terminating to slightly enlarged, ovate mouth.

Pronotum black, lateral corner of humerus reddish brown, with pale yellow pile. Scutum black, yellowish-grey pollinose, moderately covered with short, recumbent, pale yellow 
pile that is longer laterally and posteromedially. Scutellum brownish black, with long, erect, pale yellow hairs. Postscutellum black subshining. Pleuron black anteriorly, faintly pale grey pollinose, becoming more brownish medially and posteriorly; pleural membrane dark reddish brown; mesepimeral tuft pale yellow. Wing membrane hyaline; veins yellowish- to greyish-brown; pile of stem vein mixed with dark brown and pale yellow; base of costa with predominantly dark brown pile; rest of hairs pale yellow; fringe of calypter and alar lobe pale yellow. Halter greyish brown with dark brownish yellow pile. Legs varying from light brownish black to black, segments with two sorts of hairs, predominantly yellow hairs and some of dark brown ones, except for tarsi which have black hairs, tarsal brush black; hind basitarsus swollen, but spindle-shaped; both sides of its segment subparallel; about 3.5-3.7 times as long as width; 2.7-2.9 times as long as the width of 2 nd tarsal segment.

Abdomen black, with moderately dense yellowish-brown pile; hind margin of tergites narrowly greyish brown; basal fringe extremely long, black, tips of those hairs often light brownish-grey; tergite $\mathrm{X}$ small, about as long as width; sternites with moderately long, brownish-black pile. Genitalia as shown in Fig. 6. Basimere about $3 / 5$ as broad as length. Distimere about $2 / 3$ as long as length of basimere, about $3 / 5$ as wide as length, slightly curving and tapering distally to an obliquely pointed apex with 2 terminal spines. Ventral plate broad, concave dorsally; in ventral view, tapering distally, apex slightly concave, with a short, rather broad, pointed ventral lip; stem of median sclerite short, rather broad; its arms moderately sclerotized; in posterior view, rather broad, abruptly truncated at ends. Plate of endoparameral organ broader than height, rounded laterally, inner margin indefinite, lightly wrinkled, moderately sclerotized.

Pupa. Length 5.7-6.8 mm. Respiratory organ (Fig. 17) $1.8-3.0 \mathrm{~mm}$, often about $1 / 3$ as long as pupa, consisting of a short, rather broad base, covered with minute spicules, and 16 filaments; base giving rise to 3 primary trunks which are rather broad dorsal, slender lateral and ventral trunk; dorsal trunk widely divergent from lateral and ventral trunk, usually as long as ventral or lateral trunk, branching into 3 secondary trunks, a medial and a lateral trunk with 3 filaments respectively, and between them a longer trunk with 2 filaments; ventral and lateral trunk running near by parallel, bearing 2 paris of filaments respectively, one of total 4 pairs on lateral and ventral trunk usually sessile, the other pairs petiolate; filaments greysh brown, slender and slightly tapering with numerous, moderately deep, transverse furrows. Head with numerous, flattened granules; antenna of female reaching hind margin of head; antenna of male extending about two-third distance to hind margin of head. Dorsum of thorax with a faint, superficial reticulate pattern and with numerous, flattened granules; 3 rather long, slender and pale dorsal trichomes and 2 lateral trichomes on each lateral half of thorax. Tergites V-IX each with a row of short, fine, posteriorly directed spines near anterior margin, but these on tergite $\mathrm{V}$ often weakly developed; those spines completely disappear on tergite IV; tergites III-IV each with 8 larger anteriorly directed spines along posterior margin; tergite IX near middle, with short setae; a few similar setae usually present in pleural membrane of segment VIII. Caudal spines moderately long, rather stout, slightly curved, situated upon slightly swollen bases, tips divergent; each with a moderately long seta at base anteriorly and same one near base posteriorly. Sternite IV without hook usually; sternites V-VII each with large hools, lateral hooks of sternites lying in pleural membrane; sternite IX often with a few scattered setae. Cocoon with a thin, loosely woven sleeve, covering most of pupa.

Larva. Length : 6.8-8.1 mm. Body dark brown to dark greyish brown. Head capsule light yellowish brown to median brown; cephalic apotome usually lighter yellowish or reddish anteromedially; head spots usually moderately dark, distinct; eye spots rather small, surrounding clear area often indistinctly differentiated from rest of general plate. Antenna as long as or slightly longer than stalk of cephalic fan, proportional 
length of segments I-IV about $8: 10: 10: 1$. Cephalic fan with $34-42$ rays. Hypostomial teeth as shown Fig. 25, median tooth slightly inclined, nearly equal in height to outer lateral tooth VII ; lateral tines of median tooth distinctly lower than highest sublateral teeth; outer lateral tooth VII slightly higher than highest sublateral teeth; sublateral tooth III nearly equal in height to sublateral tooth $\mathrm{V}$; sublateral teeth III and V strongly flanged. Postgenal cleft shallow, apex almostly truncate, con- spicuously widening posteriorly, shield-shaped. Postgenal bridge longer than hypostomium. Inner subapical margin of mandible with $8-10$ fine serrations. Maxillary palpus 2.7-3.0 times as long as width at base. Lateral plate of proleg moderately sclerotized, extending one-half length of apical segment. Rectal setulae present, simple or compound in structure. Anterodorsal arms of anal sclerite slightly longer than posteroventral arms. Posterior circulet consisting of 8-14 hooks in $64-70$ rows.

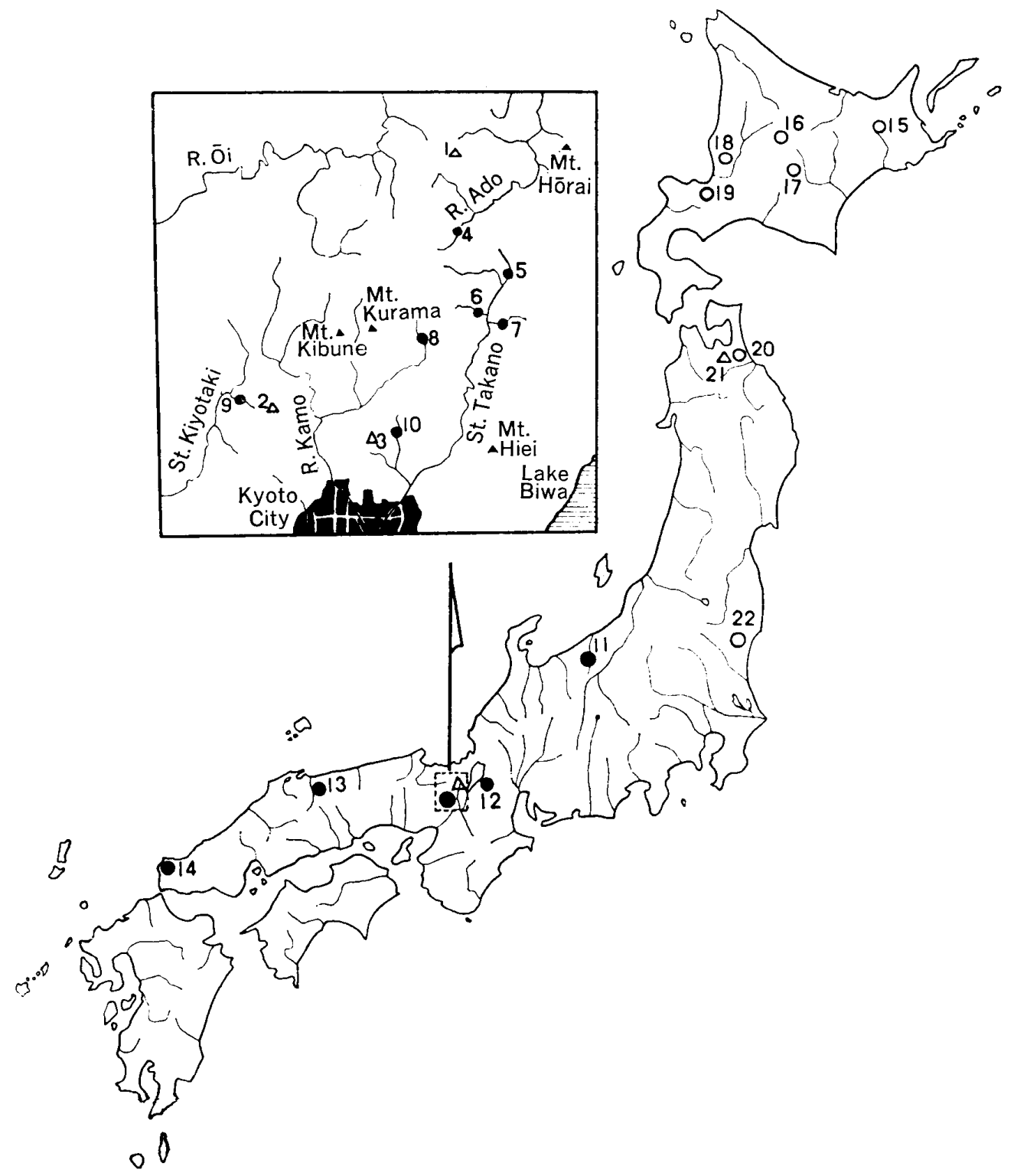

Map 1 Geographic distribution of $P$. hirtipes-group

-, P. kiotoense; $\bigcirc, P$. jezonicum; $\triangle, P$. kanii.

1, Ogose ; 2, Himuro ; 3, Amagatani ; 4, Momoi ; 5, Takano ; 6, Kusao ; 7, Kikko ; 8, Shizuhara ; 9, Sugisaka ; 10, Iwakura ; 11, Myōkō ; 12, Taga ; 12, Daisen ; 14, Nagato ; 15, Kawayu ; 16, Aizankei ; 17, Sikaribetsu; 18, Atsuta; 19, Hoshioki ; 20, Shichinohe; 21, Towada ; 22, Takahagi. 

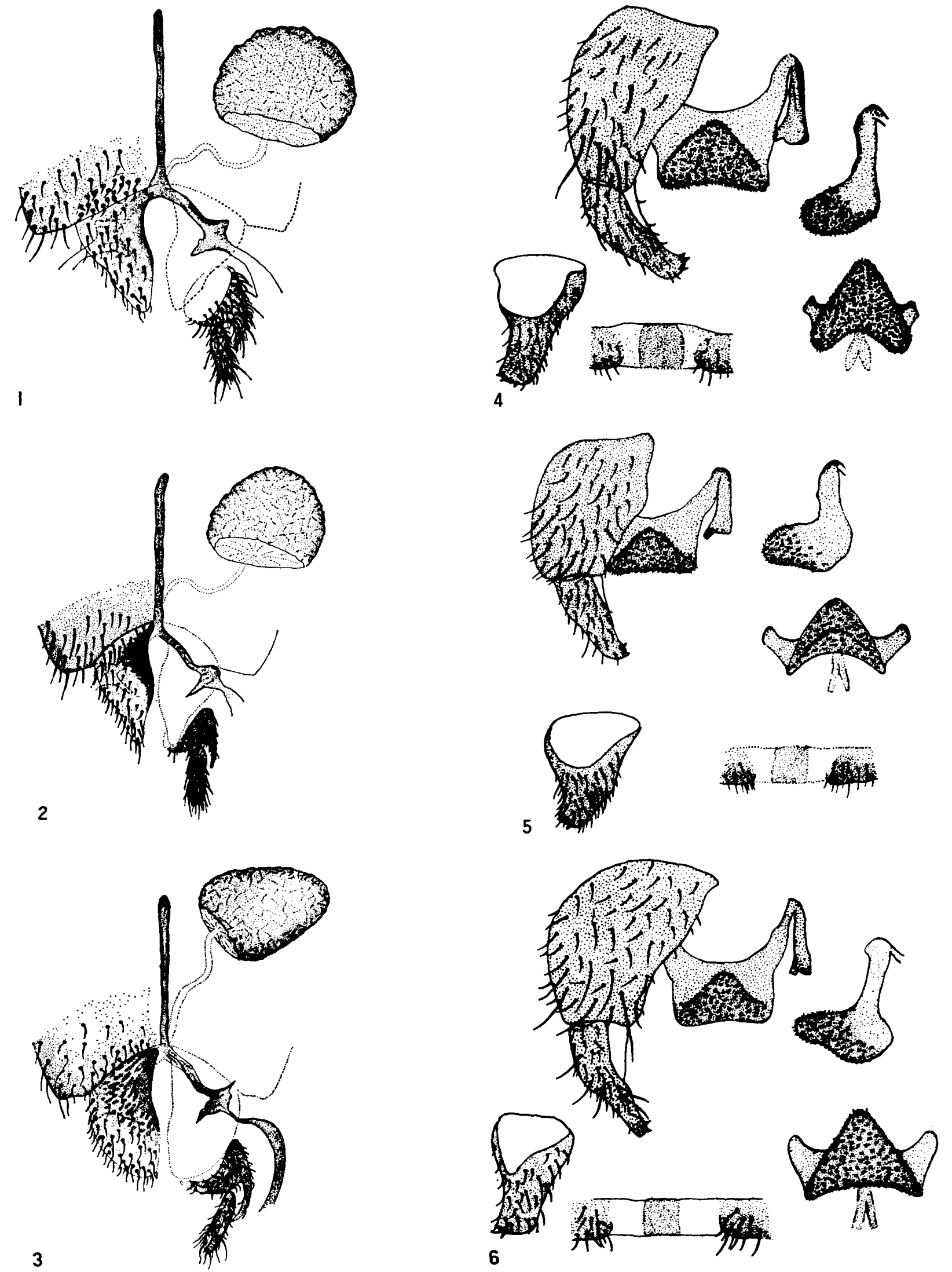

Fig. 1-6 Genitalia
1: P. kiotoense (female)
2: P. jezonicum (female)
3 : P. kanii (female)
4: P. kiotoense (male)
5 : P. jezonicum (male)
6: P. kanii (male) 

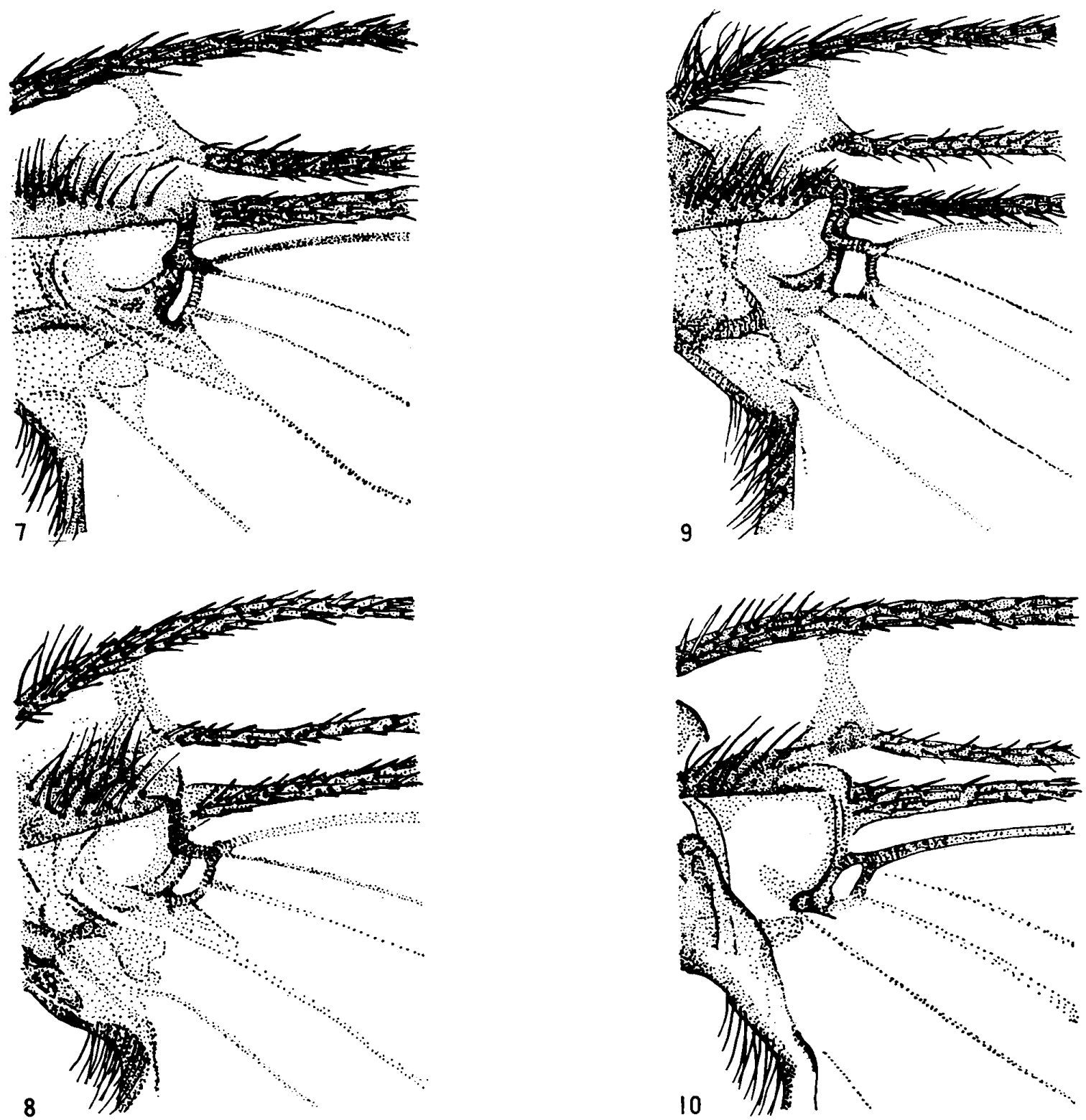

Figs. 7-10 Basal cell (female)
7: P. kiotoense
8:P. jezonicum
9: P. kanii
10: P. hirtipes
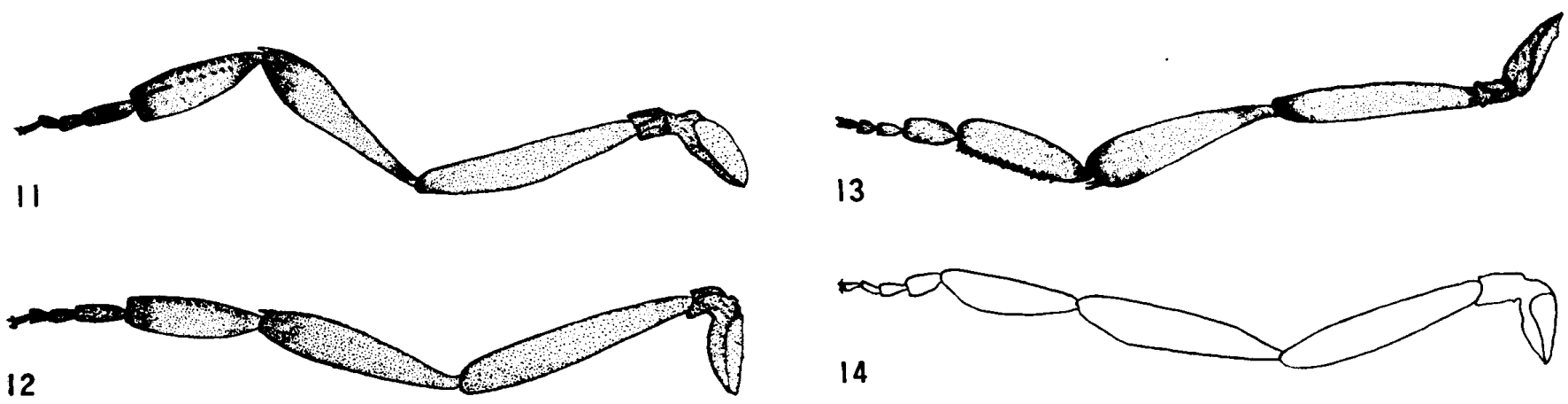

Figs. 11-14 Hind leg (female)
11: P. kiotoense
12 : $P$. jezonicum
13: P. kanii
14: P. hirtipes 

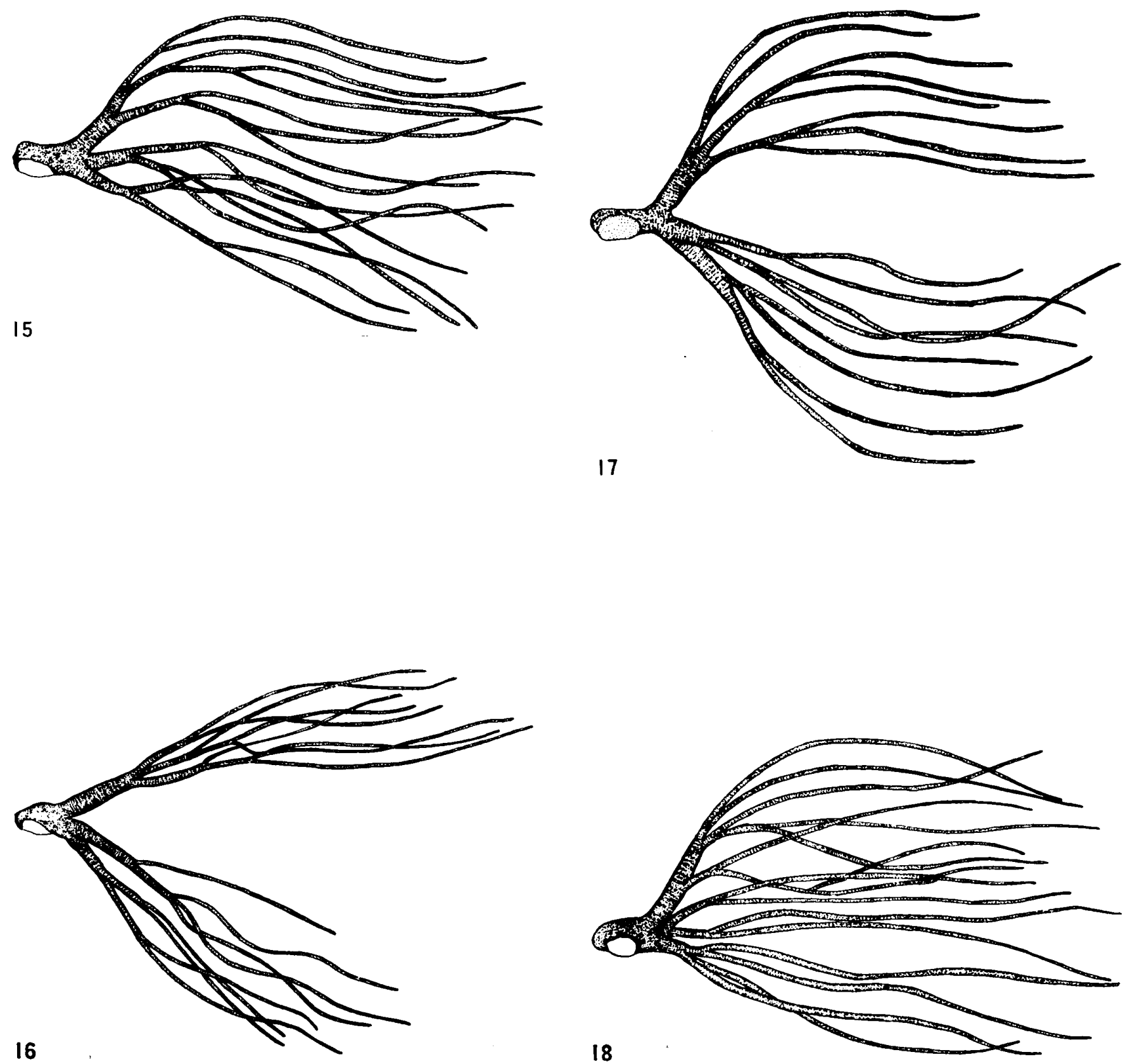

Figs. 15-18 Respiratory organ

$15:$ P. kiotoense

16: P. jezonicum

$17:$ P. kanii

18: P. hirtipes 

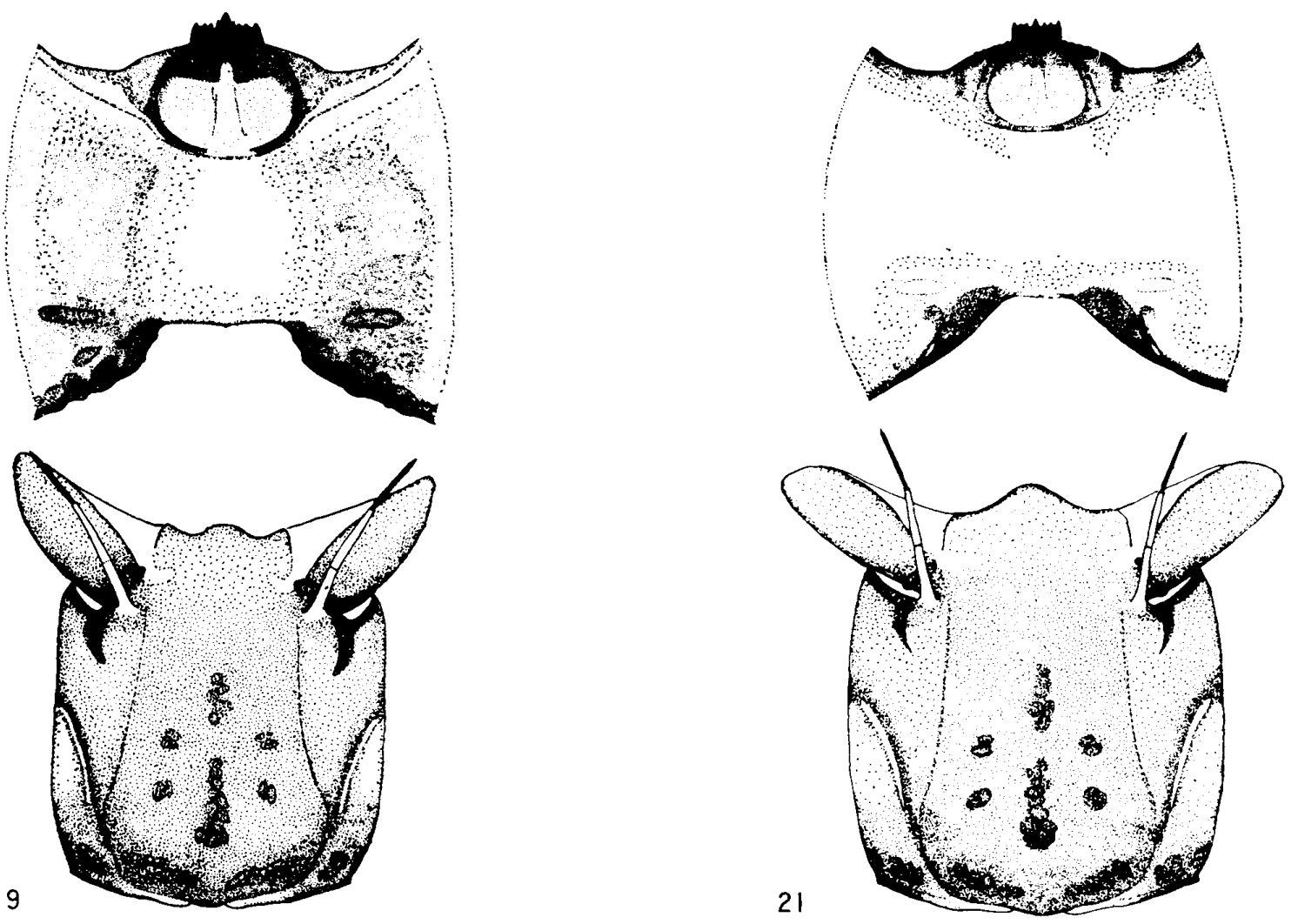

19
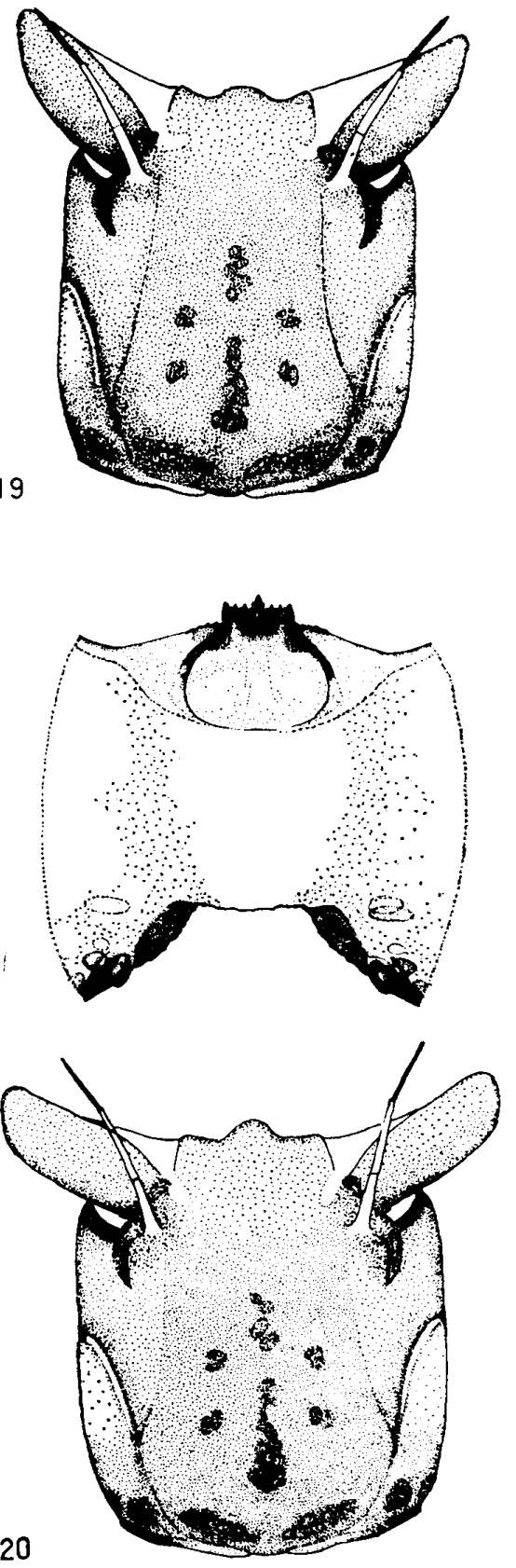

3

Figs. 19-22 Head of larva (dorsal and ventral view) 19: P. kiotoense 20:P. jezonicum 21: P. kanii 22: P. hirtipes 

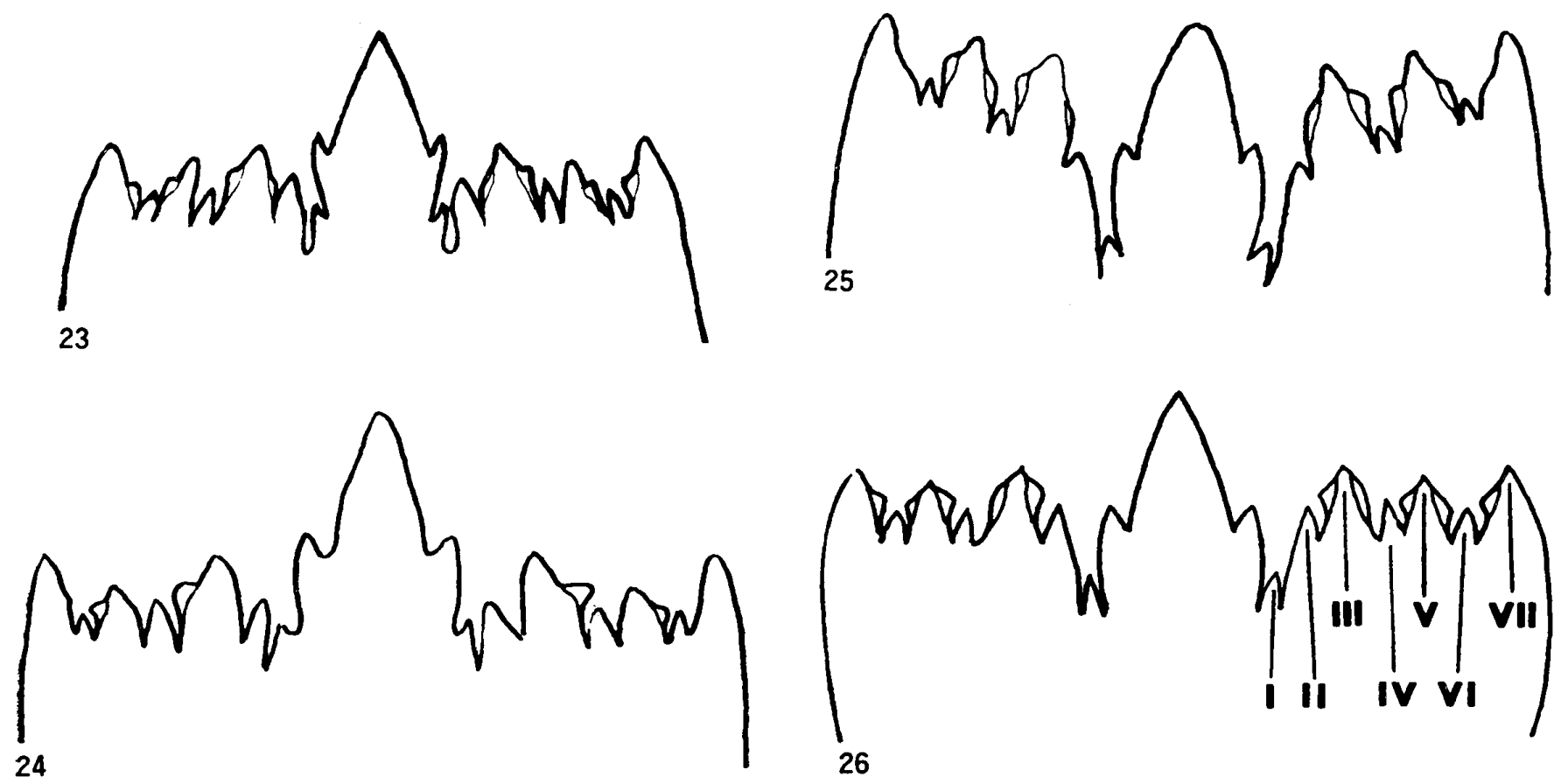

Figs. 23-26 Hypostomial teeth 23:P. kiotoense 24: P. jezonicum 25: P. kanii 26: P. hirtipes
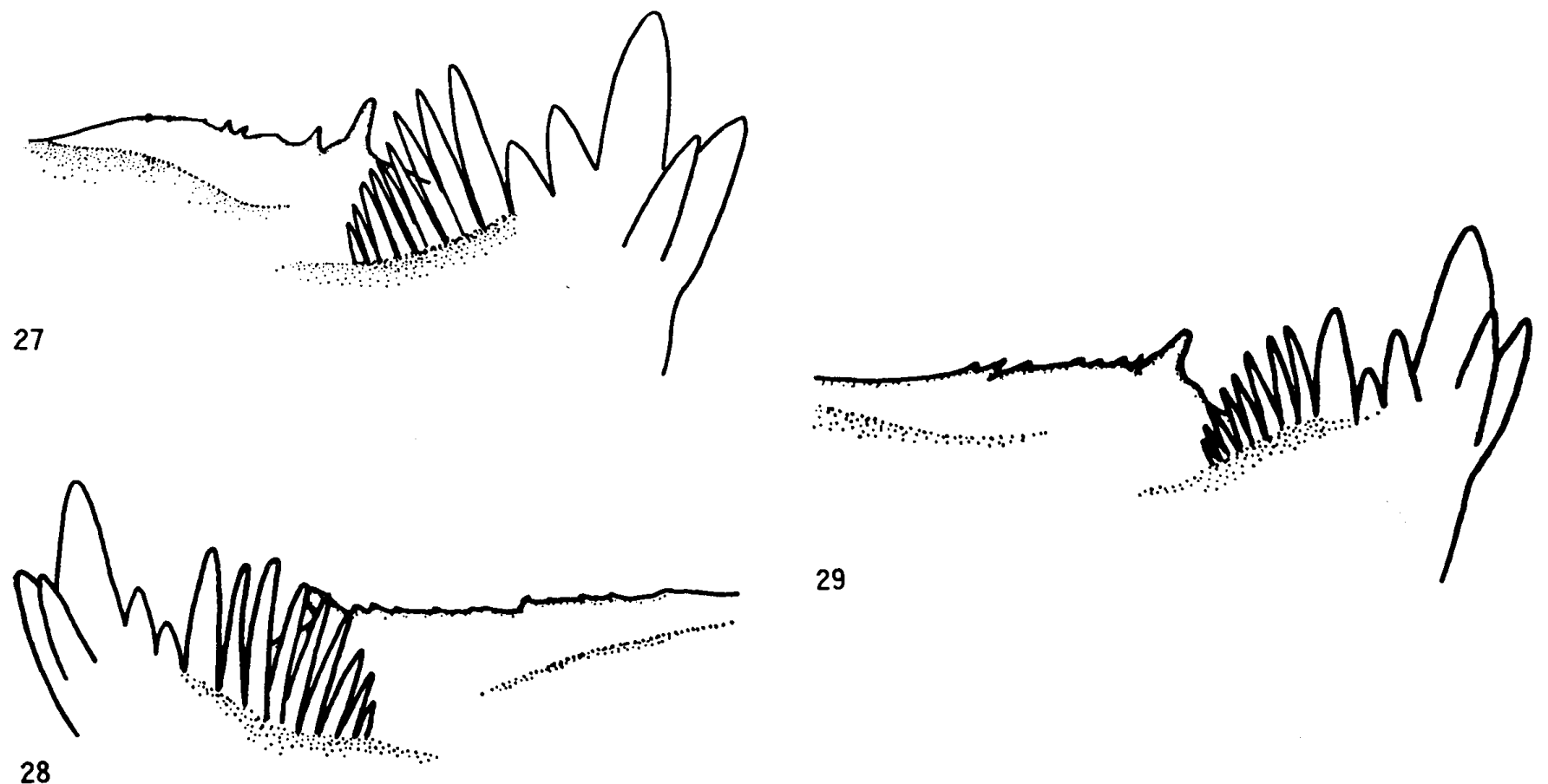

29

Figs. 27-29 Mandible of larva

27: P. kiotoense

28: P. jezonicum

29: P. kanii 
Holotype. Female (reared), Type NSMTI-Dip. No. 03757, National Science Museum Tokyo.

Type Locality. Trunk irrigation ditch crossing the main road at Himuro, Kita-ku, Kyoto, pupa collected February 22, 1972, by O. Onishi.

Allotype. Male (reared), Type NSMT-IDip. No. 03758, National Science Museum Tokyo, same deta.

Paratype. 10 females (all reared), Type NSMT-I-Dip. No. 03759, same deta; 10 males (all reared), Type NSMT-I-Dip. No. 03760, same deta; 20 larvae, Type NSMTI-Dip. No. 03761, same deta. (Above all specimens are kept in National Science Museum Tokyo.)

Paratype. 20 females (all reared), pupae collected fromtrunk irrigation ditches at Himuro, Kita-ku, Kyoto, March 27, 1971, by O. Onishi. 20 males (all reared), pupae collected from the trunk irrigation ditch at Himuro, Kita-ku, Kyoto, February 22, 1972, by $O$. Onishi. 30 larvae, same deta. (Above all specimens are kept in Department of Medical Zoology, Kyoto Pref. Medical University.)

Records (Map 1). Material examined. Kyoto city: Amagatani, Iwakura, Sakyo-ku 5-III-1965, T. Orii ; Himuro, Kita-ku, 18-III1968, K. Uemoto and O. Onishi ;-, 27-III1971, O. Onishi ;-, 22-II-1972, O. Onishi ; Ogose, Ohara, Sakyo-ku, 24-III-1971, K. Uemoto and O. Onishi (Above all are collected from irrigation ditches running between paddy fields.)

Towada city: trunk irrigation ditch crossing Route 102 at Jyuniri, 23-IV-1970, K. Uemoto (larva only).

Remark. The larvae of $P$. kanii are similar to those of $P$. mixtum and $P$. fontanum from North America, or P. irritans from the Coastal-state, U.S.S.R., in the form of hypostomial teeth, but can be distinguished from those species by widely divergent pupal respiratory organ, and by male and female genitalia. Also, this species is readily separated from other species in $P$. hirtipesgroup of Japan by the characters given in the key. $P$. kanii is sporadically distributed as shown in Map 1, but this species might be found more commonly than before, if extensive surverys will be made in winter and early spring seasons at various places.

Biological Notes. Prosimulium kanii is a univoltine species that overwinters in larval stage. In Kyoto, the larvae of this species are found during from early December to late March. The breeding sites are distinctly different from those of $P$. kiotoense or $P$. jezonicum, and the larvae and pupae have been found only in smaller, extremely sluggish stream, like irrigation ditches for paddy fields, on a upper basin among the mountains. The females have well developed mouthparts, though they have never been observed biting from humans.

\section{ACKNOWLEDGMENTS}

To Dr. H. Takahasi, we are grateful for the presentation of materials of Prosimulium hirtipesgroup from Japan and $P$. hirtipes (Fries) from Norway, and for the useful suggestions on our work. We would like to thank Dr. K. Ogata for the helps in seeing many literatures and his collections, and to show our appreciations to Dr. S. Asahina and Dr. Y. Asanuma for their advices about the designation of type specimens.

$\mathrm{We}$ are also indebted to the following people for generously sharing their collections : Dr. K. Hattori, Public Healty Institute Hokkaido; Mr. T. Okazawa, Zoological Institute, Faculty of Science, Hokkaido University; Mr. Y. Tabaru, Sankyo Co., Ltd. ; and Mr. N. Kumasawa, Public Health Department, Kyoto City.

Finally, we wish to express our thanks to Dr. G. Nakata for his help in the preparation of the manuscript.

\section{REFERENCES}

Crosskey, R. W. (1969) : A re-classification of the Simuliidae (Diptera) of Africa and its islands. Bull. Brit. Mus. (Nat. Hist.) Ent., 14: 188.

Kani, T. (1944): The studies on sanitaly pests III. On pupae of 11 species of black flies (Simuliidae) breeding from the river basin Kamogawa, Kyoto. Seiri Seitai, Zool. Inst. Fac. Sci. Kyoto Uhiv., $11: 1-8$.

Kani, T. (1952): Ecological studies on imature insects breeding in stream. Kiso Ōtaki-gawa Konchushi, 216 pp. Kiso Kyoiku-kai, Hukushima.

Kono, H. and H. Takahasi (1940) : Die Simuliiden von Sachalin und Hokkaido. Ins. Matsu- 
murana, $16(2,3): 79-82$.

Matsumura, S. (1915) : Konchu Bunruigaku II, 50 pp. Keiseisha, Tokyo.

Matsumura, S. (1915) : Dai Nippon Gaichu Zensho, II, Rokumeikan, Tokyo. 83 P1. XI, figs. 295.

Medical General Laboratory U. S. Arm. (1955) : The black flies of Japan and Korea. 23 pp., figs. 33, Tokyo.

Ogata, K. and M. Sasa (1954) : Taxonomic notes on Simuliidae or black flies of Japan, with species references on the Subgenera Eusimulium Roubaud and Nevermannia Enderlein (Diptera). Jap. J. Exp. Med., 24 : 325-333.

Ogata, K. and Sasa, M. (1955) : Key to the adult females and Pupae of Japanese Simuliidae and notes on the control of black fly larvae by insecticides (Studies on black fly 6). Jap. J. Sanit. Zool., 6 (1): 10-18.

Okamoto, M. (1958): Studies on the species and distribution of black flies in San-in district. $J$. Yonago Med. Assoc., 9 (4) : 566-579.

Orii, T. et al. (1964): Studies on the black fly (Simuliidae) in the northern suburbs of Kyoto V. Distribution and seasonal prevalence of larvae and pupae of Simulium in Kyoto. Sanit. Injurious Insect, 8 (1-12) : 36-59.

Peterson, B. V. (1970): The Prosimulium of Canada and Alaska (Diptera : Simuliidae) $\mathrm{Mem}$.
Ent. Soc. Canad., 69 : 216.

Shiraki, T. (1935): Simuliidae of Japanse Empire. Mem. Fac. Sci. \& Agr. Taihoku Imp. Univ., 16 (1) : 1-90, Pls. 14.

Shogaki, Y. (1956) : A list of Japanese Simuliidae, with special notes on a new Subgenus Nipponsimulium. Jap. Zool. Magz., 65 (7) : 274280.

Watabe, A. et al. (1956): Studies on the control of blackfly in Mt. Mys̄kj Area. Jap. J. Sanit. Zool., 7 (3, 4) : 203-207.

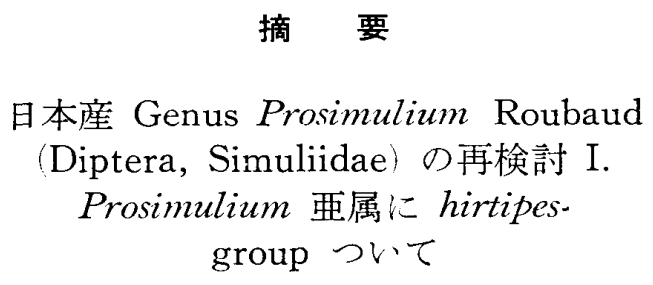

日本各地で得られた $P$. hirtipes-group に属する標本 を詳細に検討した結果，わが国で 1954 年以来，P. hir tipes (Fries, 1824) とされていたものは，北欧産 $P$. hirtipes (Fries) とは明らかな差異があり，京都産と北 海道産のものとの間にも差異が認められた。そこで, 京 都産，北海道産のものをそれぞれ，P. kiotoense Shiraki 1935, P. jezoenicum (Matsumura, 1931) とし, これら の再検討と, $P$. hirtipes-group に属する新種 P. kanii の記載を行ない，以上の 3 種の key を与えた. 